\title{
Narración, resistencia y sentido en Hannah Arendt y Gilles Deleuze
}

\section{Narrative, resistance and sense in Hannah Arendt and Gilles Deleuze}

\author{
Ángeles Ma. del Rosario Pérez Bernal \\ Adso Eduardo Gutiérrez Espinoza \\ Universidad Autónoma del Estado de México, México
}

Resumen: En este estudio se realiza una comparación de las posiciones de Hannah Arendt y Gilles Deleuze con respecto a la importancia de la narratividad como medio para resistir y dar sentido a la vida humana. Tanto Arendt como Deleuze sostendrían que el ejercicio de la escritura es un medio para resistir al totalitarismo y a la banalidad del mal, en términos de la filósofa judeoalemana, o una manera de hacer clínica de una sociedad enferma que busca asfixiar cualquier clase de vitalismo individual, en palabras de Gilles Deleuze.

Palabras clave: narratividad, comprensión, clínica, sentido, resistencia.

Abstract: In this study, a comparison is made of the positions of Hannah Arendt and Gilles Deleuze with respect to the importance of narrative as a means to resist and give meaning to human life. Both Arendt and Deleuze would argue that the exercise of writing is a means to resist totalitarianism and the banality of evil, in terms of the German-Jewish philosopher, or a way of doing clinic of a sick society that seeks to suffocate any kind of individual vitalism, in the words of Gilles Deleuze.

Keywords: Narrative, Comprehension, Clinic, Sense, Resistance.

Recibido: 27 de junio de 2018

Aceptado: 10 de octubre de 2018 


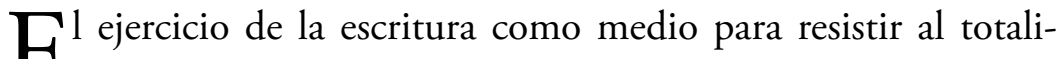
Ctarismo ${ }^{1}$ y a la banalidad del mal, ${ }^{2}$ o como una manera de hacer clínica a una sociedad enferma, cuyo propósito es asfixiar cualquier clase de vitalismo individual, son ideas que unen a Hannah Arendt (Hannover, 1906-Nueva York, 1975) y Gilles Deleuze (París, 1925-1995). Dos filósofos que detectan los límites de la teoría y la filosofía y comprenden que la literatura es una forma de conocimiento que puede ir más allá y explicar el mundo después de Auschwitz. Para quien ejerce la crítica literaria es muy interesante constatar que dos filósofos reconocen el papel primordial del arte literario como herramienta para aprehender de la realidad y parten de él para construir sus posturas teóricas. El propósito de este estudio es comparar las ideas de la filósofa judeoalemana y del pensador francés acerca de la importancia de la literatura como medio para resistir y dar sentido a la vida humana.

\section{Literatura: narratividad y cuerpo sin órganos}

Arendt explica la actividad de narrar como un ejercicio de comprensión política. Contar una historia demanda dinamismo y creatividad, disposiciones opuestas al estatismo intelectual ofreci-

${ }^{1}$ Hannah Arendt entiende el totalitarismo como el eclipse de la política; como la destrucción de las condiciones y de la capacidad de actuar, así como de la mera posibilidad de la diversidad humana, del juicio y de la razón. El totalitarismo -agrega- es el epítome del colapso de la sociedad y de las relaciones sociales; se trata de un proceso de disolución universal que reemplaza al Estado en nombre del movimiento totalitario en sí mismo, de su ideología y de su régimen de terror (Cf. Rensmann, 2014)

${ }^{2}$ La tesis de la banalidad del mal sostiene que la gente común y corriente, influenciada por motivaciones triviales, ordinarias y egoístas puede, sin embargo, convertirse en cómplice de acciones malvadas. Arendt rechaza la noción de que la maldad necesariamente presupone intenciones monstruosas (Cf. Mahony, 2018: 49). 
do por la teoría. Un relato necesariamente presupone la idea de comunidad, pues implica un narrador, un protagonista y una audiencia. En este sentido, la narración determina una de las ideas clave del pensamiento arendtiano: el libre pensamiento sólo es posible en la presencia de otros, en medio de una comunidad, más que en la silenciosa meditación teórica (Swift, 2006).

En este sentido, Arendt muestra una férrea oposición a la codificación que intentan imponer las teorías a la historia. La acción revolucionaria no puede ser predicha ni prefigurada. En cambio la narración sólo es posible luego de que los sucesos ocurrieron: privilegiar la narración sobre la teoría, es permitir a la acción desarollarse con espontaneidad y sin expectativas.

En La condición humana (2016), Arendt explica que dado que dicha condición es limitada permite que el sujeto sea narrable. Sin embargo, el propio protagonista no puede contar su historia, pues ésta sólo se completa cuando muere. La comunidad es testigo de la vida completa del individuo y es la que puede expresar su sentido. Por tanto, somos dependientes de los otros y de su percepción sobre aquello que nos distingue, la cual es inaccesible para nosotros.

La función de la narrativa con respecto a la acción, para Arendt, es que a través del arte y los relatos, la acción de los miembros de una comunidad puede ser conocida, entendida en su significado por el grupo. El sujeto sólo actúa bajo una ilusión ideológica; sólo la comunidad puede otorgarle un sentido pleno a la acción del héroe.

En el mundo moderno, la filosofía descree de que las acciones de los individuos tengan sentido en sí mismas y prefiere pensar en fuerzas impersonales que las controlan. Para Arendt esta visión platónica se ha vuelto normativa en la actualidad, postura ante la que muestra un vehemente rechazo.

En la modernidad -agrega-, el trabajo ha invadido la esfera de lo público de tal manera que el individuo se halla entre dos polos: el trabajo y el consumo. La mitad de tiempo lo ocupa en producir 
el dinero que gastará en la otra mitad. De este modo, la biología y el metabolismo del individuo se ve reducido a estas dos actividades, convirtiéndolo en un preso de sí mismo, pues la vida en comunidad se cancela (2016).

Ante esta perspectiva, el arte es el último producto de la actividad humana que se mantiene distinto del trabajo; el último objeto que no produce comodidad. El arte abre la posibilidad de imaginar diferentes modos de vivir, cuyo predicado no sea la soledad, la infelicidad y la completa consumación del esfuerzo físico del individuo. La obra de arte se distingue por su durabilidad y se opone al ciclo de trabajo-consumo. Los relatos toman la acción como su materia prima para darle durabilidad y permanecer en la memoria (2016: 184-191).

La convergencia de Arendt y Deleuze en este punto se hace patente a través del concepto cuerpo sin órganos $(\mathrm{CsO})$ que, en términos generales, consiste en esa posibilidad de salir de la molaridad, de permitir que la singularidad pueda manifestar sus potencias y atreverse a seguir las líneas de fuga que éstas trazarían. El CsO implica asumir que no hay seres acabados, ni definidos de una vez por todas por alguna doctrina filosófica o teológica, sino en constante composición y recomposición, que la última palabra sobre alguien sólo puede ser dicha cuando éste haya muerto. La vida, para Deleuze, es inmanencia ${ }^{3}$ y el ser, haecceidad, es decir, singularidad impersonal en incesante restructuración. Un sujeto en devenir es un nómada, ya que se desterritorializa y se reterritorializa sin cesar. No se detiene, no se establece, no echa raíz. Esto no significa que literalmente se esté cambiando de domicilio, sino una actitud

${ }^{3}$ La inmanencia es entendida por Deleuze como algo que no está determinado por ningún principio exterior, ni trascendente, ni ajeno a su situación o actuar concretos. Para Ferrater Mora, una actividad es inmanente a un agente "cuando permanece dentro del agente en el sentido de que tiene en el agente su propio fin" (Ferrater, 1981: 1703). 
vital, abierta, franca, expansiva, capaz de dejarse sorprender y de seguir con asombro los vericuetos, las variaciones, los nuevos afectos que descubre en sí mismo y en su ambiente.

La idea de $\mathrm{CsO}$ lleva aparejada la de línea de fuga, ${ }^{4}$ que es una elusión definitiva de lo molar. El desencadenamiento de una línea de fuga implica que lo molar ha sido sometido a la crítica y, como resultado, ha quedado socavado. En el mismo orden de ideas, un $\mathrm{CsO}$ se halla en un despliegue intenso de sus máximas potencialidades. El feto es el ejemplo por excelencia para Deleuze, ya que pasa por múltiples mutaciones que lo asimilan con otras especies, acentuando su indefinición, y que lo violentan con una intensidad tal que un cuerpo adulto acaso no las soportaría. El CsO es aquel cuerpo capaz de poseer la plasticidad para anular la predeterminación -muchas veces cultural- de sus funciones y poder asumir otras modalidades de acción, acoplamiento o articulación.

En este orden de ideas, converge el concepto $\mathrm{CsO}$ con la idea del arte como posibilidad de salir del circuito producción-consumo a través de la narratividad. Este circuito aísla y aliena al individuo impidiéndole estar en contacto consigo mismo y sus necesidades. Asimismo detiene toda posibilidad de que el sujeto se integre en comunidad y, por tanto, abre la puerta al totalitarismo. Recordemos que los sistemas totalitarios privan a la personalidad humana de cualquier condición que le permita ejercer su libertad o manifestar su espontaneidad.

${ }^{4}$ Para Deleuze y Guattari, los fenómenos y los entes pueden explicarse a partir de tres líneas: las molares, las moleculares y las de fuga. Las líneas molares son esas estructuras que se han vuelto asfixiantes y no permiten al grupo social evolucionar hacia nuevas posibilidades; usualmente lo molar se identifica con lo institucionalizado. Las línea moleculares, por su parte, producen cierta erosión en lo molar, lo socavan, pero no tienen la suficiente fuerza para destruirlas; en cambio, las líneas de fuga hacen estallar definitivamente lo molar, dando paso a desterritorializaciones que abrirán nuevas posibilidades de organización del caos. 
Por consiguiente, la civilización occidental, aun en nuestros días, se halla en la antesala del totalitarismo. Y el arte, la posibilidad de narrar, el ejercicio de la imaginación son los pocos medios con los que se cuenta para evitar una nueva tragedia.

\section{Literatura: comprensión y clínica}

La recompensa de relatar historias -dice Arendt- es poder dejar que se vayan (2008: 105). Asimismo, afirma que ella escribe para comprender y la comprensión implica alcanzar el punto equidistante entre razón y sentimiento para juzgar un suceso. Ello sólo es posible mediante una facultad: la imaginación, que permite tomar distancia del hecho, mirarlo en perspectiva, con desapego, para poder narrarlo y, a través de ese acomodo del acontecimiento en una historia, obtener una brújula para orientarnos en el mundo (2005).

Para explicar la imaginación como fuente de la actividad estético-literaria, Arendt recurre a Kant, quien en su Crítica del juicio señala que el tema de la belleza está estrechamente ligado a lo social, pues el interés por lo bello sólo puede ocurrir en comunidad. La experiencia estética parte del individuo pero lo hace partícipe del grupo social al querer compartirla con otros.

Tanto para Kant como para Arendt, los objetos artísticos y los juicios estéticos muestran lo que determinada sociedad es, a la par que develan al hombre como un ente social. En este sentido, la imaginación juega un papel primordial en la apreciación de la obra de arte y en la definición de la identidad social: nos permite pensar (o imaginar) cómo es el mundo desde la perspectiva del otro. La imaginación es pues, para Arendt, inherente a la empatía. Para Kant, al emitir juicios estéticos estamos en posibilidad de superar lo que es más privado e incomunicable sobre nuestra experiencia del mundo (Cf. Swift: 2009). Kant asevera que mientras estemos 
atrapados en lo sensorial para emitir un juicio, éste no será estético; es necesario desapegarnos del hecho para extraer su quintaesencia y alcanzar la experiencia de lo bello. Se trata de lograr un estado estático, desinteresado, mediante el poder de la imaginación. La imaginación nos coloca en un estado de suspensión con respecto a lo temporal, a lo corporal, a lo espacial, para permitirnos pensar desde una perspectiva más general.

La imaginación nos transporta fuera de nosotros mismos y de nuestros petits affaires personnels; ${ }^{5}$ nos coloca por encima de nuestros juicios parciales y nuestras motivaciones, permitiéndonos ganar una actitud desinteresada hacia la belleza. Para Arendt, este estado desinteresado nos inserta en la comunidad. Superamos lo privado, lo subjetivo, lo natural para acceder a una experiencia estética que une a la comunidad en una cultura común. Así pues, la narración, el ejercicio literario, es colocado por ella como el cemento de la comunidad. Se trata de un acción que permite a la polis ordenar los eventos acaecidos en su interior y dar cuenta de su lugar y su sentido en el mundo.

En síntesis, la narración ofrece la posibilidad de unir el pasado y el futuro, convirtiéndose el medio para transitar de manera significativa entre estos dos puntos.

By bringing to light the human, political character of events, stories invite us to acknowledge the past as something which is part of our own world and for which responsibility needs to be assumed. Yet, they also liberate us from its grasp by kindling the awareness that it could have been otherwise and that is therefore possible to create anew and differently (Mrovlje, 2014: 84). ${ }^{6}$

${ }^{5}$ Así denomina Deleuze a la novela moderna fallida (Cf. Deleuze/Parnet, 1996). 6 "Al sacar a la luz el carácter humano y político de los acontecimientos, las historias nos invitan a reconocer el pasado como algo que forma parte de nuestro propio mundo y del cual es necesario asumir la responsabilidad. Sin embargo, también nos liberan de su alcance al hacernos conscientes de que podría haber 
A conclusiones similares llega el filósofo francés Gilles Deleuze, quien en obras como Kafka. Por una literatura menor, o Crítica y clinica, expresa su interés por la palabra literaria como un mecanismo que sirve para conservar o restablecer la salud de un grupo social.

La escritura es un ejercicio en el cual el autor construye puentes para entender y ordenar, aunque sea un poco, con el fin de delimitar el caos, aquello incomprensible e incierto para el ser humano (Deleuze/Guattari, 1997: 202). De manera equiparable al científico o al filósofo, el artista traza planos en el caos buscando otorgarle un sentido. En el proceso artístico, el escritor enfrenta el desorden y siente el peso de su propia indefensión, pero recoge sensaciones que integra a su arte como materia de salud. La literatura es una composición caoidea: es un caos compuesto y en cierto modo ordenado que se ha vuelto sensible. Un texto literario formado por ciertas construcciones sintácticas, ciertos personajes que funcionan de uno u otro modo, unos espacios y un tiempo indicados tienen la potencia para generar nuevas experiencias, placenteras o no, que confronten al individuo.

La literatura comunica y construye un diálogo nacido del mismo escritor: él se desprende de sí y dialoga, primero consigo mismo y después con sus lectores, a través de la obra literaria, empleando los elementos poéticos que tiene a su alcance: los personajes y la manera de enunciar o transformar el lenguaje. Estos desprendimientos dialógicos - para Deleuze (1996) - funcionan de manera binaria: son singularidades que representan un colectivo, formando así un juego de pliegues que se estiran o se retraen. En consecuencia, lo singular se extiende hasta convertirse en un modelo de mundo.

Un escritor no es un enfermo, pues la enfermedad es un dique que evita la circulación del flujo (1996), sino más bien es un temerario que

sido de otra manera y que, por lo tanto, es posible crear de nuevo y de manera diferente"; la traducción es nuestra. 
se enfrenta con la enfermedad y el caos para volverse un médico para sí, para otros y para el mundo (14). Su iniciativa implica también un real interés por generar salud a través de inventar lo que falta. "Literature, then, is both becoming and fabulation, the prolongation of lines of flight and the invention of a people, through which possibilities of life are set free and health restored" (Bogue, 2013: 302). ${ }^{7}$

Falta, primordialmente, un pueblo, una comunidad que encarne esa voz adelantada a su tiempo que es la del escritor. Una comunidad que realmente sea tal: común-unidad y no un bloque social en el que cada individuo se halle alienado y atrapado en la dinámica irracional del consumo. Falta un pueblo capaz de razonar, imaginar y comprender, y sólo puede suceder recurriendo a la narración, a la literatura, a ese mecanismo discursivo que permite unir el pasado con el futuro, tal sería la coincidencia Arendt-Deleuze.

\section{Literatura: sentido y territorialización}

Narrar, para Arendt, es una manera que tienen las culturas de ordenar la comprensión de sí mismas. Una serie de acontecimientos acomodados en un relato son fácilmente asequibles y pueden ser mejor comunicados a una audiencia más amplia y recordados por la comunidad.

Para Arendt, los relatos poseen el potencial de ofrecer un tratamiento más atento y particular a los hechos que los sistemas filosóficos o teóricos. Contar una historia es una actividad dinámica y creativa, que se opone a los modelos intelectuales estáticos ofrecidos por la teoría. La filósofa de Hannover pensaba que narrar abre la posibilidad de diferentes interpretaciones, con base en las diversas cosmovisiones de los que escuchan la historia, y también

7 "La literatura, entonces, es a la vez devenir y fabulación, la prolongación de las líneas de fuga y la invención de un pueblo, a través del cual se liberan posibilidades de vida y se restaura la salud"; la traducción es nuestra. 
la posibilidad de un final abierto, un debate inconcluso sobre el significado de la historia. "[...] El hecho de narrar una historia revela significado sin cometer el error de definirlo [...] crea consentimiento y reconciliación con las cosas tal como son realmente" (2008: 113). La narración es útil para conciliar con la tragedia y el trauma de la historia: Como diría Isak Denisen: "Se puede soportar todo el dolor si se lo pone en una historia o se cuenta una historia de él" (112).

A partir de la experiencia de Auschwitz -continúa Arendt-, se establece una relación estrecha entre la sobrevivencia y la narración: había que sobrevivir para ser testigo y contar la historia de lo que pasó en el campo de concentración. Narrar se convierte en un acto de resistencia retrospectivo de la horrible degradación a que se sometía al individuo en los campos. En una de sus obras principales, Los orígenes del totalitarismo, Arendt, mediante un acto de distanciamiento imaginativo, narró la historia de tal fenómeno para comprender lo inédito de su origen y para que el fenómeno no volviera a repetirse (Cf. Swift, 2009).

Del mismo modo, basada en los principios estéticos de la Crítica del juicio de Kant, la obra Eichmann el Jerusalem buscaba lograr lo que el tribunal no alcanzó a atisbar: que a Eichmann se le debía juzgar en su singularidad, considerando que sus acciones fueron cometidas estando inmerso en una situación extraordinaria y sin precedentes en la historia occidental. En efecto, bajo el ala del totalitarismo, el individuo es privado de pensar libremente. Así pues, el ejercicio narrativo en este libro busca realizar un juicio reflexivo ${ }^{8}$ enfocando la historia en su singularidad. Arendt se

${ }^{8}$ Siguiendo a Kant, Arendt señala que el juicio estético es reflexivo, en tanto que el juicio legal es determinante. Para el caso de Eichmann, se hubiese requerido un juicio reflexivo, basado en la singularidad del caso, para que fuese justo, ya que la situación contextual era extraordinaria y no podía valorarse a partir del marco moral y legal ordinario. 
detiene especialmente en el modo de discurrir de Eichmann, que abundaba en clichés. Tal falta de habilidad lingüística refiere a una inhabilidad de pensamiento, a una incapacidad de pensar desde el punto de vista del otro. No tenía capacidad de imaginación. El burócrata nazi no podía sentir empatía por alguien diferente, sólo podía repetir los clichés nazis que escuchó y miró reproducirse una y otra vez a su alrededor. Fuera de los valores ideológicos nazis, el mundo carecía de sentido para él, porque era incapaz de entender que existía una otredad. El totalitarismo había hecho su parte en él -como en muchos alemanes- al propiciar la banalidad, producto de la irreflexión, la superficialidad y el aislamiento. Eichmann era un alienado para quien sólo existía una carrera burguesa que lo llevaría al éxito, no importando a costa de qué.

Así, a través de Los orígenes del totalitarismo y Eichmann en Jerusalem y utilizando el recurso narrativo, Arendt convierte el acto de escribir en un acto de resistencia contra la banalidad misma, a la par que abstrae un modelo para mostrar las consecuencias de no pensar, de no ser crítico, de no atreverse a salir de los lugares comunes. La única garantía de la supervivencia de la humanidad es ejercer de manera sistemática el razonamiento tanto en el ámbito privado como en el de la convivencia social.

El tema del sentido en Hannah Arendt a través del ejercicio narrativo guarda importantes afinidades con la categoría de la desterritorialización de Gilles Deleuze y Félix Guattari. En Mil mesetas. Capitalismo y esquizofrenia (2008) los pensadores franceses dedican varios capítulos a tal tópico, así como en otros libros como ¿Qué es la filosofía? (1997) y Crítica y clínica (1996). El territorio, afirman, tiene que ver, primordialmente, con la animalidad, la cual guarda una relación directa con el arte. Siguiendo la línea de Nietzsche, quien plantea que el arte es una actividad fundamentalmente animal, porque se relaciona con la delimitación territorial, los autores galos abundan diciendo que el artista opera en analogía 
con el animal, ya que también establece un territorio al crear el objeto estético. En efecto, el cuadro del pintor es un territorio, como lo son los límites del texto literario. ${ }^{9}$ No obstante, una paradoja se abre, porque el objeto artístico a la vez que territorializa, desterritorializa el paradigma sociocultural en que surge, desautomatizando conceptos, creencias, cosmovisiones. En sí mismo, el objeto artístico podría considerarse una zona de estabilidad, pero significa, a la vez, la desestabilización de los valores del grupo social del que surge. No obstante, esta actividad posibilita la renovación, el crecimiento, la expansión y una respuesta vitalista a concepciones molares y estandarizadas.

El territorio posee entonces un valor existencial, pues circunscribe el campo de lo familiar, marca las distancias con la otredad y protege del caos. Deleuze y Guattari consideran que el territorio es el ingrediente principal para constituir un estilo y con ello crear un objeto artístico. En este tenor, es el animal el que finca las bases del arte con sus movimientos y marcas territoriales, porque el fenómeno estético, dicen, es ante todo un agenciamiento territorial. ${ }^{10}$ Por consiguiente, para ellos hacer arte $-\mathrm{o}$ interpretarlo- plantea realizar cartografías. Anne Sauvagnargues explica que Deleuze propone una "bioestética original" en la que:

El arte no es un rasgo antropomórfico, no es lo propio del hombre, sino que debe ser comprendido conforme a la lección de Nietzsche, es decir, como fenómeno vital. Allí donde Nietzsche funda la creación en la potencia de la voluntad, Deleuze, lo mismo que Uexküll, Ruyer y Leroi-Gourhan, piensa el arte como agenciamiento territorial, algo que es propio, no de la vida, sino

\footnotetext{
${ }^{9}$ Ya Aristóteles hablaba de que el artista realiza con su obra un corte al caos de la naturaleza y que el texto literario tiene límites: unidad de tiempo, de acción y de lugar.

${ }^{10}$ El agenciamiento actúa como un equilibrio momentáneo entre acontecimiento y permanencia, entre lo variable y lo durable.
} 
del animal que posee un territorio y una casa, es decir, que agencia materias expresivas en una operación vital tributaria de la territorialización (Sauvagnargues, 2006: 140).

$\mathrm{Al}$ agenciar un territorio, el animal pasa del hábito, que es contemplación pasiva, a la habitación, construcción activa y expresiva. Este acto es llamado por Deleuze y Guattari ritornelo, el cual contiene "una descripción de la subjetivación dirigida a crear un 'centro frágil e incierto', un en-casa, un mundo habitado que refuerza las síntesis pasivas del hábito. Del hábito a la habitación se pasa del caos al territorio" (2006: 142).

La correspondencia con la concepción arendtiana de narratividad como instauradora de sentido es patente; la filósofa judeoalemana apunta, siguiendo a Kant que la apreciación de las cosas bellas tiene el poder de hacernos sentir como-en-casa en el mundo. Por tanto, va en contra de la alienación a la que tristemente induce el pensamiento filosófico tradicional en Occidente.

\section{Coda}

Resistir proviene del latín sisto, detener, permanecer inmóvil. Es un poder que suspende y detiene la potencia en su movimiento hacia el acto. La narración, mediante la imaginación, suspende; en sentido amplio, convierte un cuerpo ordinario, alienado, en un cuerpo sin órganos, desterritorializado, desestructurado, sin líneas molares que lo organicen y jerarquicen. Este primer movimiento prepara un terreno abierto para la comprensión en términos de Arendt, o la clinica, en palabras de Deleuze y Guattari.

La comprensión implica una escucha atenta, una acogida del punto de vista del otro, un aceptación; quien comprende abre espacio, acompaña, concilia. No obstante, la comprensión también tiene una parte activa: prende; es decir: selecciona, remueve, labra, trasfigura, se apropia y recrea. Quien comprende instaura un senti- 
do a partir del cual se descifra transmutado, el sentido de los otros. Este proceso es el del pensamiento en acción, que se construyedeconstruye (Cf. Kristeva, 2013).

La comprensión o clínica se precipita en el tercer movimiento, comentado en este estudio: el sentido o territorialización. Luego de ponerse en el lugar del hecho relatado, de abrirse a él, para luego asirlo, recrearlo y resignificarlo, aparece un nuevo sentido en el que está incluida la pluralidad de las voces no oídas. Pero nadie sale inerme de este proceso: todos los implicados se resignifican y se reestructuran ante esta nueva comprensión, de modo que las cosmovisiones y valores se transforman y los individuos atisban en su propia carne la anhelada comunidad que viene, el pueblo que falta.

\section{Bibliografía}

Arendt, Hannah, 2005, Ensayos de comprensión, Caparrós, Madrid. ,2008, Hombres en tiempos de oscuridad, Gedisa, Barcelona. ,2016, La condición humana, Paidós, México.

Bogue, Ronald, 2013, "Deleuze and Literature", en Daniel W. Smith y Henry Sommers-Hall, The Cambridge Companion to Deleuze, Cambridge University Press, Cambridge.

Deleuze, Gilles, 1996, Critica y clinica, Anagrama, Barcelona. , 1997, ¿Qué es la filosofía?, Anagrama, Barcelona. , y Claire Parnet, 1996, Dialogues, Flammarion, París. , y Felix Guattari, 2008, Mil mesetas. Capitalismo y esquizofrenia, Pre-textos, Valencia.

Ferrater Mora, José, 1981, Diccionario de filosofía, Ariel, Barcelona.

Kristeva, Julia, 2013, El genio femenino. La vida, la locura, las palabras. Tomo 1. La vida. Hannah Arendt o la acción como nacimiento y como ajenidad, Paidós, Buenos Aires. 
Mahony, Deirdre Lauren, 2018, Hannah Arendt's Ethics, Blumsbury, Londres.

Mrovlje, Maša, 2014, "Narrating and Understanding”, en Patrick Hayden, Hannah Arendt. Key Concepts, Routledge, Nueva York.

Rensmann, Lars, 2014, "Totalitarianism and Evil", en Patrick Hayden, Hannah Arendt. Key Concepts, Routledge, Nueva York.

Sauvagnarges, Anne, 2006, Deleuze. Del animal al arte, Amorrortu, Buenos Aires.

Swift, Simon, 2009, Hannah Arendt, Routledge, San Bernardino, California. 